\title{
Ground validation of oceanic snowfall detection in satellite climatologies during LOFZY
}

\author{
By CHRISTIAN KLEPP ${ }^{1 *}$, KARL BUMKE ${ }^{2}$, STEPHAN BAKAN ${ }^{3}$ and PETER BAUER ${ }^{4}$, \\ ${ }^{1}$ Meteorologisches Institut der Universität Hamburg, Germany; ${ }^{2}$ Leibniz-Institut für Meereswissenschaften \\ (IFM-GEOMAR), Kiel, Germany; ${ }^{3}$ Max-Planck Institut für Meteorologie, Hamburg, Germany; ${ }^{4}$ ECMWF, Reading, UK
}

(Manuscript received 7 August 2009; in final form 12 April 2010)

\begin{abstract}
A thorough knowledge of global ocean precipitation is an indispensable prerequisite for the understanding of the water cycle in the global climate system. However, reliable detection of precipitation over the global oceans, especially of solid precipitation, remains a challenging task. This is true for both, passive microwave remote sensing and reanalysis based model estimates. The optical disdrometer ODM 470 is a ground validation instrument capable of measuring rain and snowfall on ships even under high wind speeds. It was used for the first time over the Nordic Seas during the LOFZY 2005 campaign. A dichotomous verification of precipitation occurrence resulted in a perfect correspondence between the disdrometer, a precipitation detector and a shipboard observer's log. The disdrometer data is further pointto-area collocated against precipitation from the satellite based Hamburg Ocean Atmosphere Parameters and fluxes from Satellite data (HOAPS) climatology. HOAPS precipitation turns out to be overall consistent with the disdrometer data resulting in a detection accuracy of 0.96 . The collocated data comprises light precipitation events below $1 \mathrm{~mm} \mathrm{~h}^{-1}$. Therefore two LOFZY case studies with high precipitation rates are presented that indicate plausible HOAPS satellite precipitation rates. Overall, this encourages longer term measurements of ship-to-satellite collocated precipitation in the near future.
\end{abstract}

\section{Introduction}

For a successful understanding and modelling of the global climate system an in-depth knowledge of the global water cycle is mandatory (Chahine, 1992). Measuring the required quantities is, however, still a challenging task especially over the global oceans with a generally insufficient spatial and temporal coverage by ship and buoy observations. The advent of satellite platforms provided the opportunity to retrieve global data sets with an equally dense spatial distribution over sea and over land. Especially since the availability of passive microwave radiometers in space, the derivation of several essential water cycle components, and particularly of precipitation, became possible with acceptable accuracy over the global oceans (Levizzani et al., 2007). In principle, these data sets can be combined to estimate the global ocean freshwater flux. This is a highly desired but difficult task, as different data sources have to be combined, which leads to inconsistent results (Schlosser and Houser, 2007; Trenberth et al., 2007). Furthermore, no comprehensive in situ data are available (Oki, 1999).

\footnotetext{
* Corresponding author.

e-mail: christian.klepp@ zmaw.de

DOI: $10.1111 /$ j.1600-0870.2010.00459.x
}

One of these urgently required quantities having largest uncertainties in satellite and model data is oceanic snowfall. Solid precipitation is an important contributor to the hydrologic cycle and hence the global energy budget. Especially during the cold season at high latitudes the high fraction of snow and graupel can dominate the annual amount of precipitation. As recommended by the International Precipitation Working Group (IPWG, www.isac.cnr.it/ipwg/), ground validation of solid precipitation at high latitude oceans is of high priority (Ebert, 2005). State-of-the-art satellite retrievals and reanalysis data sets still disagree on global precipitation amounts, patterns, variability and temporal behaviour (Andersson, 2009), with the relative differences increasing in the poleward direction. The estimation of frequency of occurrence and amounts of mixed-phase precipitation and snowfall is most challenging as results by Klepp et al. (2003 and 2005) indicate for North Atlantic cyclones and its post-frontal precipitation. Hence, satellite based retrievals for the estimation of instantaneous pixel-level mixed-phase precipitation need to be ground validated to assess retrieval accuracy across the wide range of synoptic conditions that lead to precipitation.

This calls for ship based precipitation validation data using instruments capable of measuring amounts of rain and snowfall even under high wind speed conditions. Such oceanic data is 
rare but is urgently required for ground validation of satellite products, especially in remote regions with infrequent reports from voluntary observing ships (VOS). Furthermore, such data need to be unbiased in terms of high impact weather and hence require ships that do not circumvent storms.

The usage of ship-based gauges is, however, problematic. Quantitative measurements of snowfall over land surfaces (Lundberg and Halldin, 2001) and gauge data from a variety of countries at high latitudes, collected within the Global Precipitation Climatology Center (GPCC; Rudolf and Schneider, 2005) show that the wind induced flow distortion may yield precipitation rate errors exceeding $100 \%$ at wind speeds beyond 10 $\mathrm{m} \mathrm{s}^{-1}$ (Yang et al., 1999). As largest errors are related to high wind speeds, which prevail over the wintertime mid to high latitude oceans basins, totalisators, gauge-type disdrometers and impact-type disdrometers are not suitable for this task (Bumke et al., 2004). Also the Parsivel optical disdrometer (Löffler-Mang and Joss, 2000) and the flying Parsivel sonde turn out to give unrealistic results in the presence of substantial accelerations that are omnipresent on a ship due to high sea state (Mahlke, 2007). The instrument's optical measurement volume, illuminated by an infrared light emitting diode, is defined as the sensitive volume. It depends on the spatial orientation, which is changing continuously on a moving platform like a ship. Therefore, these instruments are not suitable for use onboard ships.

Großklaus et al. (1998) developed an optical disdrometer ODM 470, used for this study, at the IFM-GEOMAR in Kiel, Germany, that meets the shipboard usage requirements. The ODM 470 is used in the present study to obtain measurements over the cold season high latitude oceans for first validation attempts of satellite derived precipitation data.

The Lofoten Cyclone campaign (LOFZY 2005) was the first wintertime experiment targeted on air-sea interaction of individual cyclones offshore the Lofoten Islands of Norway in February and March 2005. The Norwegian Sea is a region of intense atmosphere-ocean interaction in which cyclones play an important role in the exchange of latent heat and freshwater during the cold season (Sorteberg et al., 2005). Hence, this field campaign was ideally suited to test the potential for generating high latitude precipitation data for satellite validation. To this end, the research vessel R/V Celtic Explorer was equipped with the ODM 470 optical disdrometer with the aim of point-to-area collocation against three satellite derived climatologies, HOAPS-3 (Andersson, 2009), the Global Precipitation Climatology Project (GPCP; Huffman et al., 1997; Adler et al., 2003) one degree daily (1DD) data set, and the Goddard Profiling algorithm, version 2004 (GPROF 2004; Kummerow et al., 2001).

Section 2 summarizes the development and recent status of the optical disdrometer ODM 470 used on board R/V Celtic Explorer with focus on the techniques for the derivation of the disdrometer rain and snowfall rate and the ancillary shipboard precipitation data used. Also the passive microwave satellite climatology HOAPS is described with focus on the pixel-level precipitation parameter along with a summary of ancillary satellite data used. The LOFZY 2005 field campaign is described in Section 3, followed by the point-to-area ground validation results in Section 4 using dichotomous verification and two case studies. Section 5 gives a summary and draws conclusions.

\section{Shipboard and satellite precipitation data}

\subsection{Shipboard ODM 470 optical disdrometer}

As mentioned in the introduction the uncertainties of estimating both frequency and amounts of precipitation from space grow largest at high latitude oceans especially during the cold season. This calls for a ground validation instrument capable of measuring shipboard liquid and frozen precipitation under all-weather conditions including high sea-states, high relative wind speeds, and irregular flow patterns around the ship's superstructure.

The optical disdrometer of Großklaus et al. (1998) is today called ODM 470 (Fig. 1) and is commercially available from Eigenbrodt Environmental Measurement Systems near Hamburg, Germany. It was successfully validated to measure liquid and solid precipitation even under strong wind conditions (Großklaus, 1996; Bumke et al., 2004). Lempio et al. (2007) further developed the snowfall algorithm and applied the disdrometer measurements during an intercomparison field campaign in Uppsala, Sweden in winter 1999/2000. Comparison with gauge data and manual measurements showed reliable instrument performance.

The measurement principle of the ODM 470 disdrometer is light extinction of an infrared light emitting diode at $880 \mathrm{~nm}$ wavelength caused by hydrometeors passing through a cylindrical sensitive volume of $120 \mathrm{~mm}$ length and $22 \mathrm{~mm}$ diameter, which is kept perpendicular to the local wind with the aid of a wind vane. The cylindrical form of the volume causes the measurement to be independent of the incident angle of the hydrometeors (Lempio et al., 2007). The local wind speed is measured using an anemometer. The electronic signal caused by the hydrometeor is proportional to its cross-sectional area. The disdrometer measures the size of the cross-sectional area and the residence time of hydrometeors in the sensitive volume within a size range of $0.4-22 \mathrm{~mm}$. Measurements are partitioned in 129 size bins with highest resolution for small particles and a logarithmic increase in size. Collector lenses and an optical blend are used for homogeneous illumination of the sensitive volume (Fig. 1). The averaging time interval is set to $60 \mathrm{~s}$. Coincidence effects of multiple hydrometeors within the sensitive volume at the same time and edge effects of partly scanned hydrometeors are considered in the same way as for liquid phase precipitation.

The precipitation rate in $\mathrm{mm} \mathrm{h}^{-1}$ is calculated using the size bins, terminal velocity, mass of the hydrometeors and the particle size distribution density which is calculated after Clemens (2002) by particle counting given the local wind speed along with 


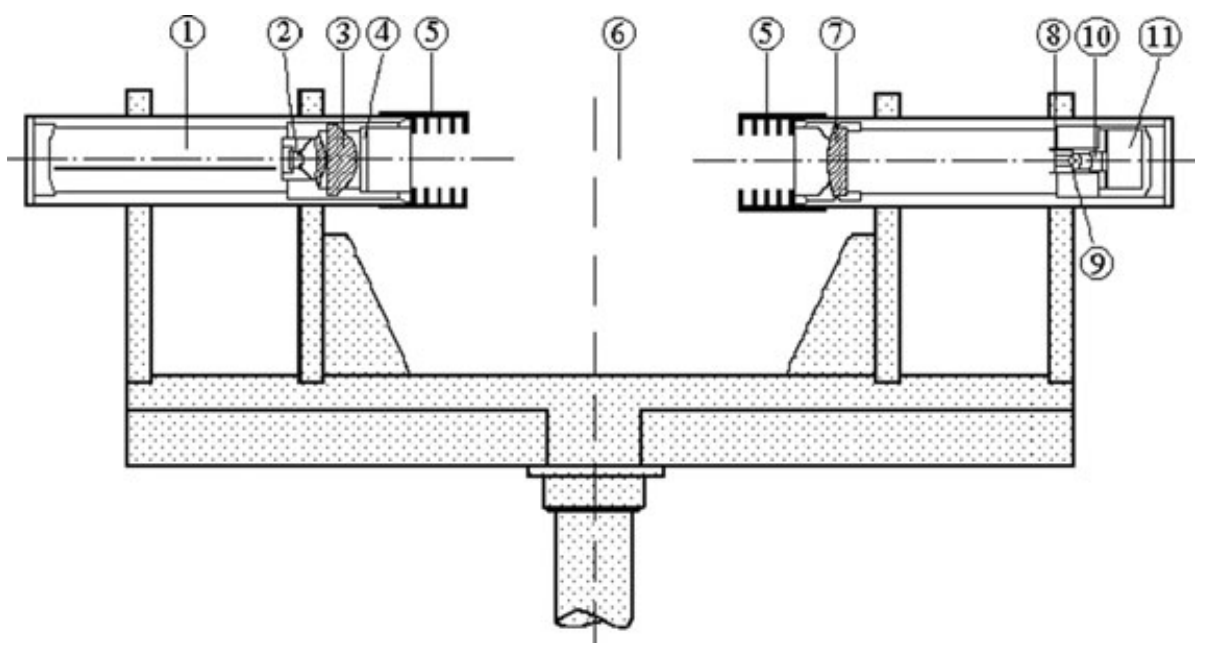

Fig. 1. Cross-section of the optical disdrometer ODM 470. From left to right: electronics (1), light emitting diode (2), lens system (3), window (4), baffles (5), sensitive volume (6), achromatic collector lens (7), optical blend (8), ocular (9), photo diode (10), electronics compartment (11).

the measuring time interval and the size of the optical volume. The determination of the rainfall rate through the liquid water content (mass) and the fall velocity is easily parametrized as rain drops have a nearly spherical shape and a constant density.

In contrast to rainfall, solid precipitation is characterized by a variety of complex shapes with different fall velocities and different equivalent liquid water content even if identical in maximum dimension. The measured cross-sectional area depends on size, shape and orientation of the solid particles hindering the development of a unique solid precipitation retrieval scheme. The relationship between mass or equivalent liquid water content and the terminal fall velocity for snow crystals is analysed by Hogan (1994) as a function of their maximum dimension. However, the disdrometer measures the size of the cross-sectional area instead of the maximum dimension of non-spherical particles. Assuming that the ice crystals fall randomly oriented through the sensitive volume (Brandes et al., 2007) and that a large sample of crystals of the same type has a repeatable mean cross-sectional area, the parametrization of Hogan (1994) can be used. This allows the derivation of a transformation function to derive the maximum dimension of the crystal type from the mean cross-sectional area and hence the equivalent liquid water content and terminal fall velocity, resulting in the snow rate in $\mathrm{mm} \mathrm{h}^{-1}$. However, the disdrometer cannot identify the type of a particle. Hence, Macke et al. (1998) developed a geometrical model to simulate different snow crystal types and a ray tracing model to determine the mean cross-sectional area out of 3000 randomly orientated projections for different sizes with regard to their maximum dimension. Lempio et al. (2007) found from theoretical experiments that the product of the terminal velocity and the equivalent liquid water content as a function of the crosssectional area of different types of snow crystals are of the same order of magnitude and allow using one common parametrization for lump graupel. As lump graupel is nearly spherical in shape, it needs no transformation function from cross-sectional area to maximum dimension. The parametrization for lump graupel is applicable for particles with a size range of 0.4-9 mm. Single precipitation events showed larger cross-sectional areas up to $22 \mathrm{~mm}$ caused by giant snowflakes. Lump graupel was the most frequently observed precipitation type over the Nordic Seas during the LOFZY campaign. Current investigations in our group indicate that if no observations of the precipitation phase are available, the shape of the size spectra of the disdrometer calibrated for solid precipitation can be used to identify rain, snow or sleet from the data.

The ODM 470, calibrated for solid precipitation measurements, was previously operated on R/V Knorr over the cold season Labrador Sea (Marshall et al., 1998) and successfully compared against other precipitation measuring devices and with manual measurements in a winter campaign 1999/2000 at the Meteorologisk Institut Uppsala in Sweden. High amounts of snowfall caused the disdrometer precipitation rates to be larger when compared to other instruments. This might result from flow distortion effects of the other instruments as the disdrometer is able to measure correctly even under high wind speeds.

During the LOFZY 2005 campaign additional ancillary ground validation data was used with the optical disdrometer. An opto-electronically infrared rain sensor (IRSS88), commercially available from Eigenbrodt Environmental Measurement System operationally measured precipitation frequency. The instrument houses two high-intensity infrared beams generating an active sensing area of about $120 \mathrm{~mm} \times 25 \mathrm{~mm}$. The system is able to detect even low density and small-sized hydrometeors that pass through the sensing area. The averaging time interval is set to $60 \mathrm{~s}$. As even the very small droplets of sea spray can be detected, this instrument can be used to distinguish between atmospheric precipitation and sea spray events when operated simultaneously with the disdrometer. 
Overall, the ODM 470 in combination with the IRSS88 is a unique system based on a robust hardware with minimal maintenance requirements that enables a complex measurement taskthe estimation of the rain and snow rate even under high wind speeds on a moving ship. This system, installed on the highest parts of the ship's mast, allows the generation of a vitally important ship-based precipitation data set for validation of remote sensing and model analysis data.

\subsection{Satellite precipitation data}

The satellite derived HOAPS climatology is the only generally available compilation of both precipitation and evaporation with the goal of estimating the net freshwater flux from one consistently derived global satellite data set. To achieve this goal, HOAPS utilizes multisatellite averages, inter-sensor calibration, and an efficient sea ice detection procedure. All 15 HOAPS variables are derived using radiances of the Special Sensor Microwave/Imager (SSM/I) radiometers, except for the sea surface temperature, which is obtained from Advanced Very High Resolution Radiometer (AVHRR) measurements. Since 1987, six $\mathrm{SSM} / \mathrm{I}$ instruments have been launched into space, which are considered to be temporally stable measuring instruments, thus providing a reliable basis for a climatological data set. Global ocean data between 1988 and 2005 of the recently released improved and extended version HOAPS- 3 is publicly available via www.hoaps.org (Andersson, 2009). Three data subsets of HOAPS-3 are available comprising scan based pixel-level data (HOAPS-S) and two types of gridded data products (HOAPS-G and HOAPS-C), allowing HOAPS to be used for a wide range of applications. The HOAPS-S data subset contains all retrieved physical parameters at the native SSM/I pixel-level resolution of approximately $50 \mathrm{~km}$ for each individual satellite, providing the basis for the gridded data products HOAPS-G (pentad, monthly and climatological) and HOAPS-C (twice-daily).

The HOAPS-3 precipitation retrieval is based on a neural network utilizing a training data set based on a one-dimensional variational retrieval that has been operated at ECMWF between 2005 and 2009 (Bauer et al., 2006a,b). The data set contains 1 month of globally assimilated SSM/I brightness temperatures and the corresponding liquid and solid precipitation amounts from the European Centre for Medium-Range Weather Forecast (ECMWF) model covering a wide variety of globally distributed rainfall events including extremes. Principally, all retrieval schemes are based on a priori data on which the neural net or regressions are trained. Whether this a priori data originates from NWP model output or other data is of little importance. It is accepted practice to use model information to relate satellite observed radiances to surface precipitation (Ferraro, 2007). It is important to validate the surface precipitation estimates, since the training data come from a model instead of observations.

A lower threshold value is applied to the HOAPS precipitation algorithm, below which the precipitation signal is considered to be zero. From experience with the preceding HOAPS precipitation algorithm, a value of $0.3 \mathrm{~mm} \mathrm{~h}^{-1}$ turned out to be an appropriate limit for distinguishing between a real precipitation signal and background noise (Andersson, 2009). The algorithm does not discriminate between rain and snowfall.

For the ship to satellite validation the pixel-level highest resolution HOAPS-S precipitation data in native SSM/I resolution of about $50 \mathrm{~km}$ per pixel is used. Due to the inhomogeneous emissivity HOAPS is devoid of data within $50 \mathrm{~km}$ off any coastline or sea-ice. Therefore, ship data within this zone is neglected. All individual descending and ascending overpasses of the SSM/I radiometers on Defense Meteorological Satellite Program (DMSP) F-13, F-14 and F-15 are used for the ground validation. This utilizes ship data between 5 and 11 UT in the morning and 14 and 20 UT in the afternoon.

For comparison, ancillary satellite data was used alongside with the HOAPS climatology. This comprises the 1DD data of the Global Precipitation Climatology Project (GPCP, Adler et al., 2003). GPCP is a combined data set that utilizes a combination of low orbit microwave and infrared satellite data along with rain gauge data from the Global Precipitation Climatology Center (GPCC, Rudolf and Schneider, 2005). Over the tropical and subtropical oceans GPCP mainly relies on SSM/I while Tiros Operational Vertical Sounder (TOVS) infrared data is incorporated to derive precipitation in the latitudinal bands from $40^{\circ}$ to $70^{\circ}$. Due to the $1 \mathrm{DD}$ resolution, the precipitation patterns of GPCP 1DD are used for plausibility control only.

The pixel-level Goddard profiling algorithm (GPROF 2004) is the current operational rainfall algorithm for SSM/I, TRMM TMI and AMSR-E. GPROF retrieves both the instantaneous rainfall and the rainfall vertical structure by using a Bayesian approach to match the observed brightness temperatures to hydrometeor profiles derived from cloud resolving models (CRM). A radiative transfer model based on a one-dimensional Eddington approximation is used to compute brightness temperatures from the CRM hydrometeor profiles at the observed satellite frequencies (Kummerow et al., 1996, 2001). However, GPROF data is only available up to $70^{\circ}$ latitude, which significantly reduces the validation sample.

AVHRR channel 4 satellites images are used from the KSAT Kongsberg Satellite Services AS receiving station in Norway for cloud analysis (http://www.ksat.no/) along with images from the Dundee receiving station for visualization of the LOFZY cloud systems.

\section{The LOFZY field campaign}

The first wintertime field experiment on cyclones over the Norwegian Sea LOFZY (Lofoten Zyklonen) was carried out within the special research project 'Cyclones and the North Atlantic climate system" (SFB512) by the University of Hamburg. The campaign's focus was on the ocean-atmosphere interaction during the passage of cyclones in the Lofoten region offshore 
Fig. 2. The cruise legs of R/V 'Celtic Explorer' during the LOFZY field campaign from 27 February and 19 March 2005. The clockwise circular pattern offshore the Lofoten Islands, Norway was sailed twice and marks the intensive operation period where solid precipitation measurements were obtained. At 7 March 2005 the ship made an overnight stop at Troms $\varnothing$, north of the Lofoten Islands. The numbers denote the days of the month ranging from 27 to 18 and the number locations indicate the ship's 12 UT position.

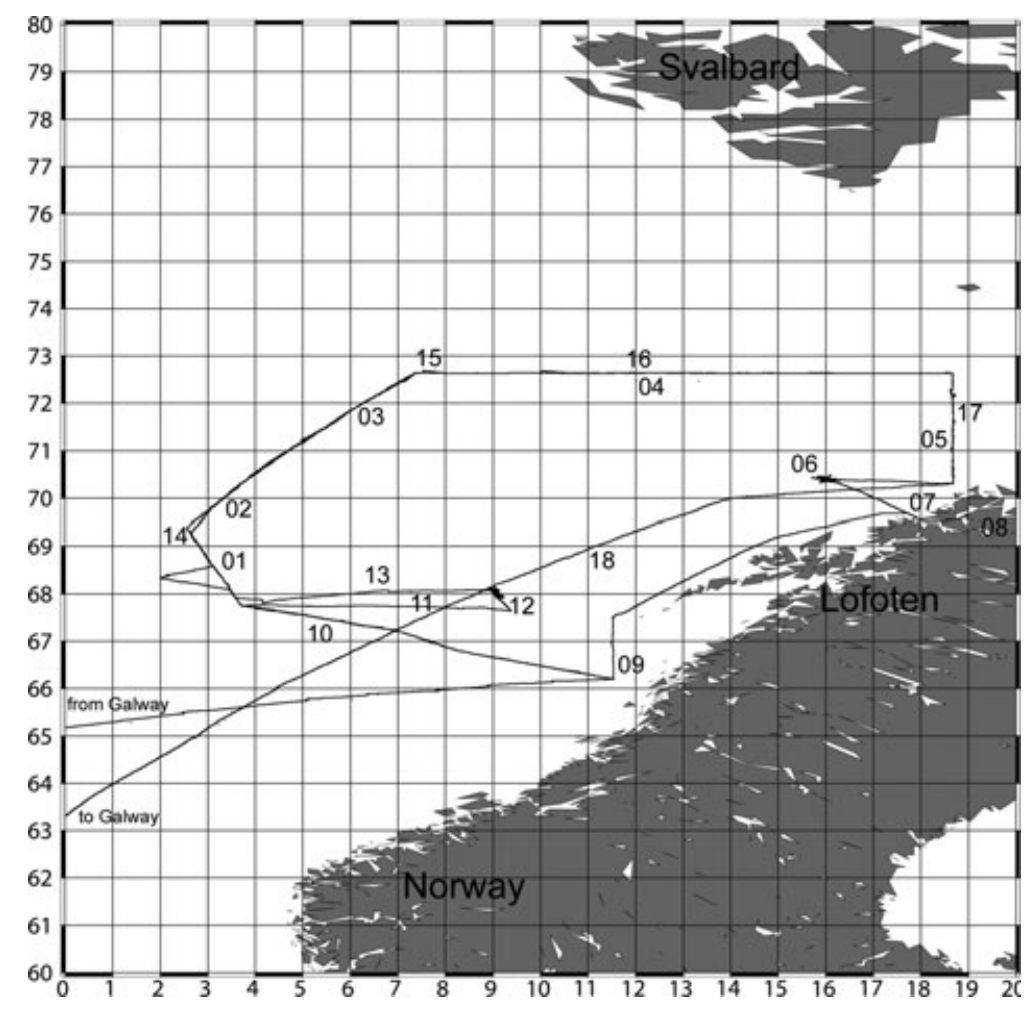

The instruments were operated throughout the entire field campaign recording the data in $1 \mathrm{~min}$ intervals and maintenance was limited to precipitation-free situations. The ODM 470 and IRSS88 were placed at the front left part of the ship's mast approximately $20 \mathrm{~m}$ above sea-level to minimize the influence of flow distortion by the ship's superstructure and sea spray contamination (Fig. 3). For detailed precipitation verification a 24 h observer's log was recorded by meteorologists in shift operation during the entire cruise with special emphasis on the overpass times of the F-13, F-14 and F-15 DMSP satellites between $5 \mathrm{UT}$ and $11 \mathrm{UT}$ in the morning and $14 \mathrm{UT}$ to $20 \mathrm{UT}$ in the evening. The log contains cloud fraction, cloud types,

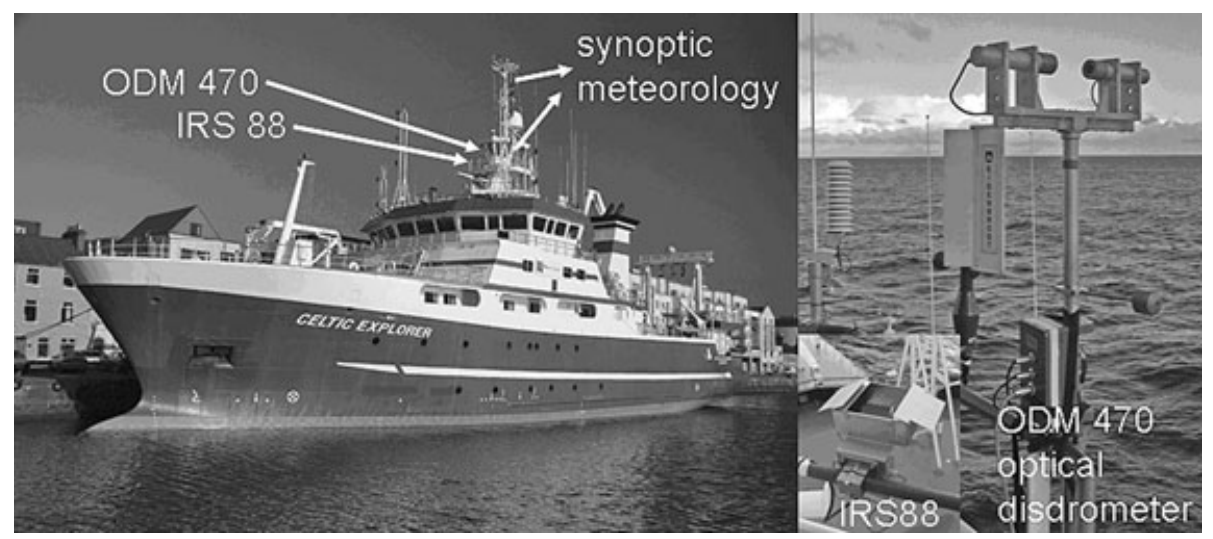

Fig. 3. The ODM 470, IRSS88 and meteorological instrument locations in the ship's mast of R/V 'Celtic Explorer' (left-hand panel) and a close-up view (right-hand panel) during the LOFZY campaign. 


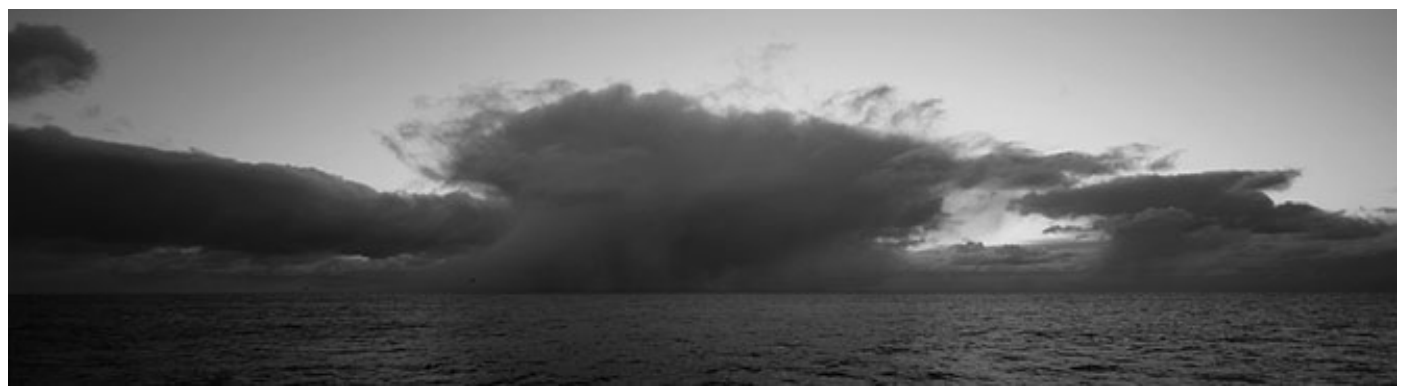

Fig. 4. Typical shallow cold air cells of polar Cumulonimbus clouds during the LOFZY cruise causing intensive convective solid precipitation. The downdraft area with heavy precipitation is to the left of the cloud centre. A second cloud anvil is visible in the distance to the right.

precipitation occurrence, duration, intensity changes and type. For solid precipitation the crystal type and crystal size was additionally observed. The ship's position and all standard meteorological parameters were recorded in $1 \mathrm{~min}$ intervals and radiosondes were launched at the synoptic hours. Cloud photography was carried out during special events.

In total, 20 measurement days of continuous disdrometer data resulted in 39 case studies of twice daily weather events according to the descending and ascending orbits of the DMSP satellites. With the constraint that the ship needs to be at least $50 \mathrm{~km}$ away from any coastline for the comparison with the HOAPS satellite data 31 case studies were used for collocation from which 7 contained no precipitation, 3 cases contained drizzle and 21 case studies comprised solid precipitation. In most of these cases lump graupel predominated, followed by snowflakes of various sizes and a few hail events. Solid precipitation was in many cases associated with convective open and closed cells within cold air outbreaks that resembled the appearance and structure of Cumulonimbus by exhibiting perfectly shaped iced anvils. Radiosonde data showed that the cloud top height was about $3 \mathrm{~km}$ with no further clouds above. These polar Cumulonimbus clouds led to numerous more or less equally distributed, scattered but intensive precipitation events with a mix of lump graupel and snow (Fig. 4). Further precipitation events encountered during the cruise comprised frontal systems, a stationary gale-force wind front (Brümmer et al., 2010), mesoscale cold air precipitation and the passage of a polar low as described in Section 4.3.

\section{Results}

The results section is subdivided into three parts. The first part describes the point-to-area collocation method between the ship and the satellite data. The second part contains a dichotomous verification using contingency tables. The collocated disdrometer and HOAPS satellite data contains precipitation values up to $1 \mathrm{~mm} \mathrm{~h}^{-1}$. In the third part, two cases studies are summarized including a polar low passage and postfrontal precipitation with observed rates up to $7 \mathrm{~mm} \mathrm{~h}^{-1}$. The aim is to show that although the strict collocation applied to the disdrometer and satellite data was not possible for these case studies, their high precipitation rates are still plausible.

\subsection{Point-to-area collocation}

For collocation, the pixel-level precipitation product HOAPS-S is used. The HOAPS precipitation retrieval itself contains a lower precipitation threshold of $0.3 \mathrm{~mm} \mathrm{~h}^{-1}$ for each individual F-13, F-14 and F-15 DMSP satellite overpass, as values below the threshold cannot be separated from the background noise (see Section 2.2). At $70^{\circ}$ North six descending and six ascending overpasses over the ship's position can be used each day. DMSP F-13 passed over the ship's position between 05:49 UT and 09:24 UT in the morning and between 14:10 UT and 17:42 UT in the evening. DMSP F-14 passed over the ship's position between 07:16 UT and 09:12 UT in the morning and between 14:53 UT and 18:15 UT in the evening. DMSP F-15 passed over the ship's position between 08:31 UT and 11:15 UT in the morning and between 16:10 UT and 19:32 UT in the evening. The ship was at least $50 \mathrm{~km}$ away from any coastline or sea-ice for $14.25 \mathrm{~d}$ during the LOFZY cruise resulting in 171 collocations between the ship's position and the three DMSP satellite overpasses.

To collocate the point measurement of the shipborne disdrometer with the highest resolution $50 \mathrm{~km}$ footprints of the SSM/I satellites experimentation is carried out using different spatial and temporal windows to understand the sensitivity of the results for different collocation criteria. Based on precipitation measurements over the Baltic Sea between 1996 and 2000 using an optical disdrometer and a shipboard rain gauges on the research vessel Alkor and several merchant ships Clemens and Bumke (2002) estimated the temporal scales of the precipitation measurements. Given that the ships move at about $15 \mathrm{~km} \mathrm{~h}^{-1}$ in average speed and based on 8-min measurements they calculated decorrelation lengths, defined as the distance at which the correlation decreases to the value of 1/e. They found decorrelation lengths of 46-68 km for stratiform and frontal precipitation and about $18-46 \mathrm{~km}$ for convective precipitation. Visible and infrared satellite images show that the Baltic Sea is infrequently covered by decaying cloud streets originating from distant cold air outbreaks. In contrast, cold air outbreaks over the Nordic 
Seas are characterized by young cellular cloud patterns organized in cloud streets that are associated with numerous more or less equally spaced convective showers. Hence, the decorrelation length of these Nordic Sea convective events can be expected to be larger compared to those over the Baltic Sea. Hence, for the ship-to-satellite collocation during LOFZY 2005 the spatial satellite criterion of the overlapping and nearest pixel and the $55 \mathrm{~km}$ radius pixel around the ship position was tested for sensitivity giving very similar results. The temporal criterion was tested from instantaneous to hourly and up to $\pm 45 \mathrm{~min}$ around the overflight time of the satellite. For these criteria, the nearest, maximum and mean value was calculated additionally. In terms of dichotomous verification and even for quantitative comparisons, the results do not change significantly depending on the criteria used. This shows that the results are fairly robust in terms of varying the constraints.

In the end, the largest temporal window of \pm 45 min centred around the individual satellite overpass is allowed for the ship's position. The satellite pixels used are constrained to a spatial window of $55 \mathrm{~km}$ radius centred around the ship's position resembling a resolution of $1^{\circ}$ in latitude and a corresponding variable resolution in longitude from $2.4^{\circ}$ to $3.4^{\circ}$. These temporal and spatial collocation constraints allow considering for moving cloud systems like fronts or cold air outbreak cloud streets with numerous convective showers both within the field of view of the satellite and the ship's route. While the ship's movement during the \pm 45 min collocation interval is fairly negligible for the point-to-area validation the temporal window can account for the atmospheric motion that has to be considered. Given a common wind speed of $10 \mathrm{~m} / \mathrm{s}$ a precipitating system can move about $54 \mathrm{~km}$ during $90 \mathrm{~min}$. This resembles the footprint size of the HOAPS-S pixels and allows neighboring satellite pixels to contribute to the collocation result. Hence, the time variability of the ship observations over a $90 \mathrm{~min}$ window is expected to be comparable to the precipitation rate variability for cases of scattered showers or any partially covered precipitation area within the satellite pixel. The HOAPS precipitation algorithm accounts for this beamfilling effect within the field of view.

\subsection{Dichotomous verification}

The statistical methods used for the dichotomous verification follow the recommendations of the WWRP/WGNE (World Weather Research Programme/Working Group on Numerical Experimentation) joint working group on Forecast Verification Research (www.cawr.gov.au/projects/verification). With the point-to-area collocation method described in Section 4.1, contingency tables were produced for dichotomous verification of the IRSS88 precipitation detector against the observer's log, ODM 470 optical disdrometer against the observer's log and the HOAPS climatology against the ODM 470 optical disdrometer (Table 1). The total of 171 collocated cases includes 52 precipitation events and 119 correct negatives, according to the observer's
Table 1. Contingency table for the dichotomous verification of the observers log against the IRS (top), the observers log against the disdrometer (middle) and the disdrometer against the HOAPS climatology (bottom) including the corresponding accuracy

\begin{tabular}{|c|c|c|c|c|c|}
\hline & \multicolumn{5}{|c|}{ Observation } \\
\hline & & Yes & No & Total & \\
\hline \multirow[t]{3}{*}{ IRSS88 } & & & & & Accuracy \\
\hline & Yes & 50 & 0 & 50 & IRSS88 \\
\hline & No & 2 & 119 & 121 & 0.99 \\
\hline Total & & 52 & 119 & 171 & \\
\hline \multirow[t]{3}{*}{ Disdrometer } & & & & & Accuracy \\
\hline & Yes & 52 & 0 & 52 & Disdrometer \\
\hline & No & 0 & 119 & 119 & 1.00 \\
\hline \multirow[t]{2}{*}{ Total } & & 52 & 119 & 171 & \\
\hline & \multicolumn{5}{|c|}{ Disdrometer } \\
\hline \multirow[t]{3}{*}{ HOAPS } & & & & & Accuracy \\
\hline & Yes & 45 & 2 & 47 & HOAPS \\
\hline & No & 5 & 119 & 124 & 0.96 \\
\hline Total & & 50 & 121 & 171 & \\
\hline
\end{tabular}

log. The contingency table for the IRSS 88 detector exhibits a nearly perfect accuracy of 0.99 with only 2 misses and 0 false alarms (Table 1 top panel). The contingency table for the ODM 470 disdrometer shows a perfect accuracy of 1.00 and hence has no misses or false alarms (Table 1 middle panel). These highly satisfactory scores draw strong confidence in the data collected. Therefore, the dichotomous verification is extended to the disdrometer and the HOAPS climatology (Table 1 bottom panel). HOAPS reaches an accuracy of 0.96 , indicating that a fraction of $96 \%$ of the HOAPS precipitation events is correct. HOAPS contains 5 misses and 2 false alarms while having 45 hits and all 119 correct negatives.

As a high accuracy is mainly determined by a large number of correct negatives, further statistical verification scores were investigated. The BIAS score points out how the frequency of the HOAPS 'yes'-events compare to observed 'yes'-events and indicates with a value of 0.94 only a slight underestimation of the HOAPS precipitation events. The probability of detection (hit rate) reaches 0.9 indicating that a $90 \%$ fraction of the observed 'yes'-events were correct in the HOAPS data. A HOAPS false alarm ratio of $4 \%$ shows that only a minor fraction of the HOAPS 'yes'-events were not measured by the disdrometer. The probability of false detection or false alarm rate of $2 \%$ reveals the minor fraction of observed 'no' that was incorrectly labelled as 'yes' in HOAPS. Interestingly, all these cases turn out to be streaks of ice-virga, according to the observer's log, that hardly reached the ground and hence were not recorded by the disdrometer while HOAPS correctly detected precipitation in these cases. 
The collocated disdrometer data has also been compared to GPROF 2004 and GPCP 1DD estimates. GPROF 2004 covers an area up to $70^{\circ}$ north. Hence 30 out of 52 precipitation events could be investigated using the DMSP F-13, F-14 and F-15 data. Out of 30 precipitation events GPROF 2004 exhibits 0 hits and 30 misses. Utilizing GPROF 2004 with AMSR-E data reduces the collocated sample to 11 events of which 0 are hits and 11 are misses. Additionally, the GPCP 1DD data that covers the entire experiment area is used. As the data is available on a daily basis a direct collocation was not possible. Hence it was investigated if any precipitation is found in the corresponding area of that day. For $11 \mathrm{~d}$ with precipitation 2 hits and 9 misses were found. Overall, the GPROF algorithm and the GPCP 1DD product are not sensitive to snowfall over the high latitude oceans during the cold season.

\subsection{Qualitative assessment for two case studies}

Overall, the dichotomous verification of the ship-to-satellite collocated values shows, that HOAPS is able to detect solid precipitation at high-latitudes during the cold season in good agreement with the optical disdrometer. However, the collocated data part of the campaign comprises only precipitation values up to 1 $\mathrm{mm} \mathrm{h}^{-1}$. High latitude solid precipitation is an important contributor to the global water cycle. Therefore, the ability of satellite products to measure intense and longer-lasting precipitation in high-impact weather events needs to be investigated, too. Collocation, however, was not possible during the limited duration LOFZY campaign. Notwithstanding, two case studies during the campaign showed the required attributes of high precipitation rates up to $7 \mathrm{~mm} \mathrm{~h}^{-1}$ and have been used for a qualitative assessment of satellite-derived high precipitation values under more extreme conditions.

4.3.1. A polar low passage on 15 March 2005. On 15 March 2005 a dual polar low system developed offshore the Norwegian coast (Fig. 5). The southerly polar low was located at $64^{\circ}$ North, $4^{\circ}$ East offshore Trondheim and exhibits a small but intense precipitation core with rates up to $3 \mathrm{~mm} \mathrm{~h}^{-1}$ according to the HOAPS climatology. The northerly polar low was located in the area offshore the Lofoten Islands at the position of R/V Celtic Explorer at $73^{\circ}$ North, $7^{\circ}$ East. Both polar lows existed for about 20 hours. Bordering just to the southwest of the northerly polar low, multiple cloud clusters occurred with a spiral curvature resembling a mesoscale complex low pressure system. This formed a temporary third polar low during the night with intense snowfall recorded by the disdrometer onboard the ship (Fig. 5a, c, d).

Between 03:55 and 06:10 UT these cloud clusters associated with this third polar low system in the vicinity of the northerly polar low passing over the position of R/V Celtic Explorer, resulting in blizzard like precipitation with a mix of graupel and snowfall, according to the observer's log. The ODM 470 disdrometer measured between 0.2 and $1.7 \mathrm{~mm} \mathrm{~h}^{-1}$ snowfall between 03:55 and 06:10 UT (Fig. 5d). The shipboard cloud observations refer to polar Cumulonimbus clouds (Fig. 4) in very short successions at the beginning and end of the precipitation event while the cloud structure was not observable during the continuous precipitation phase. At 06:10 UT the snowfall stopped. The first SSM/I satellites (F-14 and F-13) of the day covering the region passed over the ship's position at 07:45 UT and 07:58 UT. The corresponding HOAPS precipitation values of the temporary third polar low are between 0.3 and $1.6 \mathrm{~mm} \mathrm{~h}^{-1}$. The HOAPS-3 precipitation rates within the larger northern polar low show a maximum of $2.3 \mathrm{~mm} \mathrm{~h}^{-1}, 50 \mathrm{~km}$ to the west of the ship at 10:42 UT (F-15), including a spiral precipitation pattern that resembles the polar low cloud structure of the AVHRR infrared image (Fig. 5b and c). Due to the temporal mismatch of $100 \mathrm{~min}$, direct collocation between the disdrometer data and the SSM/I satellites used in the HOAPS climatology was not possible. Given the assumption that the precipitation field is just displaced and remained essentially unchanged in intensity during this temporal mismatch, the agreement between the disdrometer and HOAPS data is remarkably good. HOAPS shows the expected spiral precipitation pattern of the northern polar low with precipitation rates ranging from 0.3 to $2.3 \mathrm{~mm} \mathrm{~h}^{-1}$ along with the complex cluster pattern of the nearby third polar low (Fig. 5c). At 11 UT, the ship's position was located to the east of the northern polar low cloud head. Hence, no precipitation was measured but heavy precipitation was observed in the distance. The impressive wall of clouds including mammatus structures is shown in a stitch of three images showing almost 180 degrees in westerly direction at the image centre. (Fig. 5e).

In contrast, GPCP 1DD shows no precipitation in either of the polar lows or in the complex mesoscale low pressure system. GPROF 2004 SSM/I and GPROF 2004 AMSR-E show no precipitation associated with the complex low pressure system and the southerly polar low. The northerly polar low cannot be compared to GPROF data as data is only available up to $70^{\circ}$ North.

4.3.2. Postfrontal convective showers on 1 March 2005. The synoptic situation during a low-pressure trough episode on 01 March 2005 shows a low pressure system along the Norwegian coast situated with its core over the Lofoten Islands $(1005 \mathrm{hPa})$ by slowly moving in east-southeast direction. From there a fractured cold front extended southward into the North Sea (Fig. 6a).

In the morning R/V Celtic Explorer was below the western parts of this cold front at $68.3^{\circ}$ North and $2.2^{\circ}$ East. The disdrometer recorded snowfall mainly within two events of approximately one hour duration having a mean precipitation rate of about $0.5 \mathrm{~mm} \mathrm{~h}^{-1}$ with two short peak intensities up to $5.3 \mathrm{~mm} \mathrm{~h}^{-1}$. The HOAPS values for this cold front range from 0.3 to $3 \mathrm{~mm} \mathrm{~h}^{-1}$. To the west of the scattered cold front precipitation, a mostly cloud free area followed. In the evening R/V Celtic Explorer was at the eastern margin of the cold air outbreak that followed the passage of the low pressure system. The 

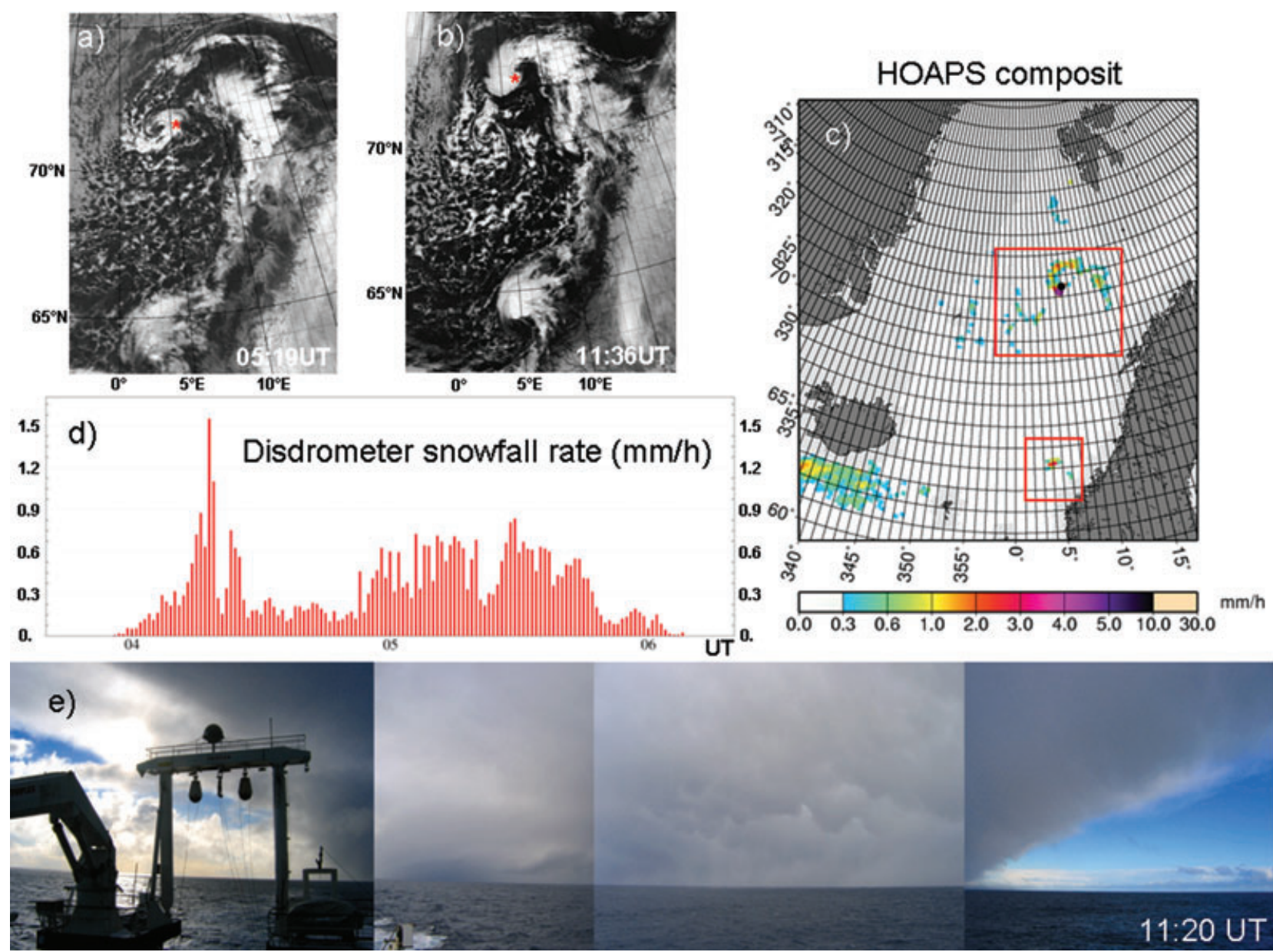

Fig. 5. Dual polar low event on 15 March 2005 offshore Norway. The red marks within the AVHRR satellite images (a, b) indicates the ship position at 05:19 UT and 11:36 UT (www.ksat.no). The HOAPS-3 precipitation composites for the F-13, F-14 and F-15 descending satellite orbits (c) is shown with the ship's position indicated by the black dot. The large red box denotes the northern polar low (spiral curvature) and the temporary third polar low in the lower left of the box. The disdrometer snowfall values (d) are given in $\mathrm{mm} \mathrm{h}^{-1}$ between 04 and 06 UT. The R/V 'Celtic Explorer' stern view of the polar low cloud wall (e) is photographed at 11:20 UT including mammatus.

AVHRR satellite image (Fig.6a) shows low-level cloud streets aligned in North-South direction that became more compact in the area of the ship's position. From 19:20 UT on, the disdrometer recorded intensifying snowfall with short interruptions that reached its maximum intensity around 23 UT with values up to $7.5 \mathrm{~mm} \mathrm{~h}^{-1}$ (Fig. 6c) out of cumulus mediocris clouds, according to the observer's log. This documents that intense convective precipitation is not only falling out of mid to high-level clouds associated with fronts, but falls in particular out of postfrontal convective clouds that resemble the polar Cumulonimbus character as presented in Fig. 4. The last SSM/I overpass of this day, covering the position of R/V Celtic Explorer was from DMSP F-15 at 19:15 UT. The ship was on the eastern brink of the postfrontal cloud field containing precipitation values from 0.3 to $7.3 \mathrm{~mm} \mathrm{~h}^{-1}$, according to HOAPS. Direct collocation of these intense disdrometer and HOAPS precipitation values is not possible. The temporal mismatch between the disdrometer recorded event and the last SSM/I overpass is 4 hours. The spatial mismatch between the ship's position and the position of the $7.3 \mathrm{~mm} \mathrm{~h}^{-1}$ event in HOAPS at the time of the last SSM/I overpass was about $180 \mathrm{~km}$ with the intense precipitation field being west-northwest of the ship's position. The average wind speed recorded onboard the ship was $10 \mathrm{~m} / \mathrm{s}$ between $19 \mathrm{UT}$ and 23:30 UT. This may account for a cloud field displacement of at least $150 \mathrm{~km}$ within 4 hours. The AVHRR satellite sequence clearly documents an eastward displacement of the corresponding postfrontal cloud system of about the same order of magnitude. Given that the precipitation intensity within the postfrontal system probably did not change significantly during these 4 hours, which is supported by the subsequent HOAPS scene, the precipitation estimates of the disdrometer with $7.5 \mathrm{~mm} \mathrm{~h}^{-1}$ may agree well to the HOAPS values of $7.3 \mathrm{~mm} \mathrm{~h}^{-1}$ (Fig. 6b, c). Again, GPROF 2004 and GPCP 1DD exhibit no precipitation within this case study. 


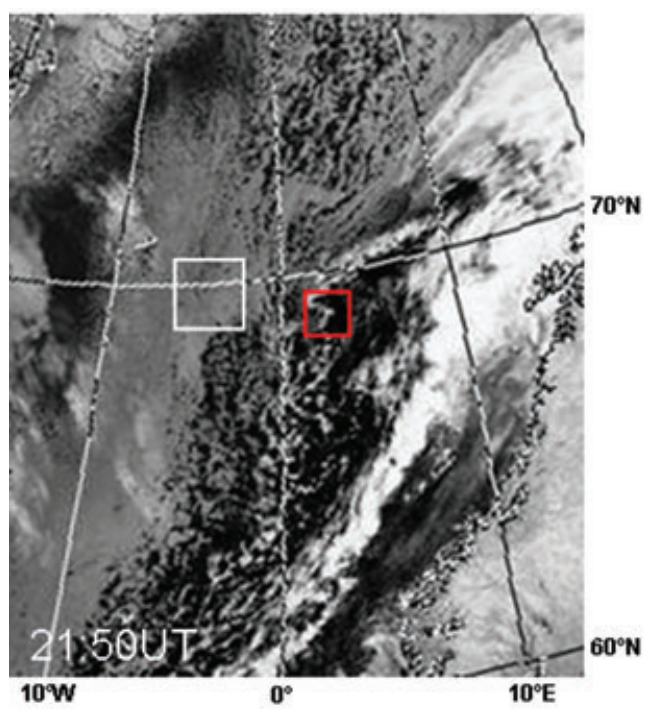

HOAPS-S 1MAR2005 F15 1915UT

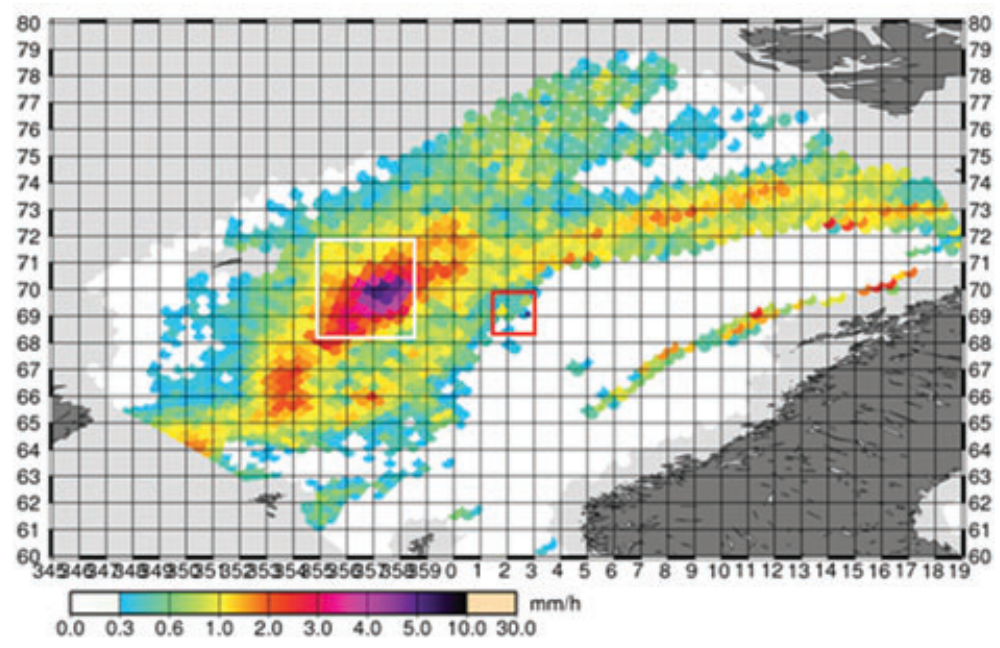

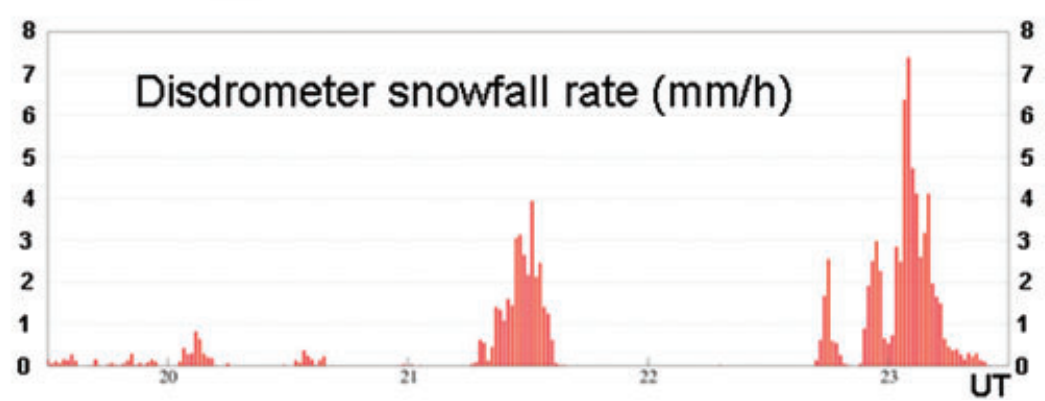

Fig. 6. The postfrontal convective shower case study from 1 March 2005. The AVHRR satellite image (a) from the Dundee receiving station at 21:50 UT is compared to the HOAPS precipitation field for F-15 at 19:15 UT (b). The red boxes indicate the ship position. The white boxes mark the position of the most intense convective postfrontal precipitation. The corresponding disdrometer data is additionally shown (c).

Although the magnitudes of precipitation seem plausible even beyond the collocation criteria, this immediately calls for longer term measurements to cover the entire precipitation spectrum for direct collocation between the disdrometer and HOAPS (see Section 5).

\section{Summary and conclusions}

A successful understanding and modelling of the global climate system requires a thorough knowledge of the global oceanic precipitation. However, the estimation of quantitative precipitation remains a challenging task for in-situ instruments, remote sensing and reanalysis systems, especially for solid precipitation over the cold season high latitude oceans. As a step towards an improvement of this situation, the optical disdrometer ODM 470 demonstrated its potential by measuring liquid and solid precipitation during the LOFZY 2005 campaign on R/V Celtic Explorer in February and March 2005 over the cold season Nordic Seas offshore Norway. For monitoring and quality control of the disdrometer data a precipitation detector was operated accompanied by a detailed observer's $\log$. During $15 \mathrm{~d}$ a total of 171 cases could be point-to-area collocated against SSM/I satellite data of the DMSP F-13, F-14 and F-15 spacecrafts. This includes 52 precipitation events and 119 correct negatives. The dichotomous verification of the precipitation frequency resulted in a perfect score between the disdrometer, the detector and the observer's log giving confidence in the collected ground validation data. The HOAPS precipitation is overall consistent with the disdrometer data with a detection accuracy of $96 \%$, a bias score of $94 \%$, a hit rate of $90 \%$, a false alarm ratio of only $4 \%$ and a probability of false detection of only $2 \%$. In contrast, GPCP 1DD and GPROF2004 data turn out to be not sensitive to solid precipitation at high-latitudes.

Some of the most interesting cases described in Section 4.2 are the events shorter than 6 min duration, where the disdrometer values are close to zero while HOAPS detects precipitation between 0.3 and $0.6 \mathrm{~mm} \mathrm{~h}^{-1}$. All these cases contained icevirga observations of snowfall in scattered showers that only partially reached the ground. Such high latitudes ice-virga observations are also described by Hobbs et al. (2001) and Wang et al. (2004). The microwave radiation emitted from these evaporating hydrometeors correctly leads to a precipitation signal in the HOAPS climatology. This leads to the question how much virga precipitation is falling on Earth and how much it might 
contribute to the total amount in satellite climatologies. In five cases the disdrometer measured precipitation while the HOAPS values were zero. These were single events during the $\pm 45 \mathrm{~min}$ interval with durations shorter than $6 \mathrm{~min}$. Such events cannot be detected in the HOAPS climatology as the precipitation is too weak or evolves too quickly to contribute significantly to the satellite signal of the $50 \mathrm{~km}$ pixel size, given that a lower threshold of $0.3 \mathrm{~mm} \mathrm{~h}^{-1}$ needs to be reached.

The significantly better performance of the solid precipitation in the HOAPS precipitation retrieval compared to other satellite precipitation products points at a fundamental issue of precipitation retrievals, namely the importance of the a priori knowledge that constrains the retrieval (see Section 2.2). Passive microwave observations of precipitation over oceans are mainly sensitive to integrated contents of hydrometeors and exhibit, except for deep tropical convection, little sensitivity to frozen hydrometeors, in particular in cold environments and shallow convection. Most retrieval algorithms that are applied to global observations are trained with datasets that rarely represent high-latitude precipitation events so that the combined effect of weak radiometric sensitivity and insufficient statistical representativeness produces unrealistic precipitation retrievals. HOAPS is the only generally available product that has been trained with global NWP model output that is-within the limits of global model physics parametrizations-consistent in terms of cloud physics and radiative transfer. Since most global NWP models produce rather realistic liquid and frozen precipitation forecasts at the surface, the HOAPS training dataset can be expected to include a much better statistical representation of precipitation than other datasets. Hence, HOAPS precipitation can be expected to be better than other satellite based precipitation datasets at high- and mid-latitudes (Klepp et al., 2003 and 2005).

The encouraging results of HOAPS detecting solid precipitation over the cold season Nordic Sea will allow for a quantitative analysis between the point-to-area collocated precipitation rates of HOAPS and the ODM 470 disdrometer. As a first attempt a separation time of $6 \mathrm{~min}$ for splitting the data set containing 52 snowfall events is selected from the observer's log and the disdrometer data, as this length of time represents the typical duration of a single cell precipitation event. The correlation between the disdrometer and the HOAPS climatology is 0.6 for precipitation events longer than 6 min. However, this analysis needs to be investigated in more detail in terms of representativeness errors associated with the point to area comparisons along with sampling and instrument errors.

The high accuracy for the collocated precipitation events during LOFZY 2005 indicates that HOAPS-3 is able to reliably detect solid precipitation at high latitudes during the cold season. Nevertheless, only precipitation events below $1 \mathrm{~mm} \mathrm{~h}^{-1}$ could be point-to-area validated. Although two additional case studies indicate that the HOAPS precipitation values are also plausible for substantially higher snowfall rates, longer term measurements covering the entire precipitation spectrum includ- ing extreme values are required. A first attempt to obtain more Nordic Sea cold season disdrometer measurements was carried out in March 2008. In close cooperation with the Bjerknes Centre for Climate Research (BCCR) and the Norwegian Coast Guard (Kystvakten) we participated in the THORPEX field campaign within the International Polar Year and operated the ODM 470 disdrometer successfully onboard K/V Senja. More such measurement campaigns and a systematic validation against active satellite systems like Cloudsat are planned for the near future in a project within the KlimaCampus at the University of Hamburg 'Integrated Climate System Analysis and Prediction' (Clisap).

\section{Acknowledgments}

This research was funded by the German Science Foundation (DFG) under grant SFB 512 'Cyclones and the North Atlantic climate system'. We thank two anonymous reviewers for their helpful comments.

\section{References}

Adler, R. F., Huffman, G., Chang, A., Ferraro, R., Xie, P. and co-authors. 2003. The version-2 global precipitation climatology project (GPCP) monthly precipitation analysis (1979-present). J. Hydrometeorol. 4, 1147-1167.

Andersson, A. 2009. The HOAPS climatology: Evaluation and Applications. Dissertation, Max-Planck Institut für Meteorologie, Reports on Earth System Science, 72, 2009, Bundesstraße 53, Hamburg, Germany, ISSN 1614-1199, pp. 178.

Bauer, P., Lopez, P., Benedetti, A., Salmond, D. and Moreau, E. 2006 a. Implementation of $1 \mathrm{D}+4 \mathrm{D}$-var assimilation of precipitation-affected microwave radiances at ECMWF: 1D-var. Quart. J. Roy. Meteor. Soc. 132(620), 2277-2306.

Bauer, P., Moreau, E., Chevallier, F. and O'Keeffe, U. 2006b. Multiplescattering microwave radiative transfer for data assimilation applications. Quart. J. Roy. Meteor. Soc. 132(617), 1259-1281.

Brandes, E. A., Ikeda, K., Zhang, G., Schönhuber, M. and Rasmussen, R. M. 2007. A statistical and physical description of hydrometeor distributions in Colorado snowstorms using a video disdrometer. J. Appl. Met. Clim. 46(5), 634-650.

Brümmer, B., Müller, G., Klepp, C., Spreen, G., Romeiser, R. and coauthors. 2010. Characteristics and impact of a gale-force storm field over the Norwegian Sea. Tellus 62A, this issue.

Bumke, K., Clemens, M., Grassl., H., Pang, S., Peters, G. and co-authors. 2004. Accurate areal precipitation measurements over the land and sea (APOLAS), BALTEX Newslett. 6, 9-13.

Chahine, M. T. 1992. The hydrological cycle and its influence on climate. Nature 359, 373-380.

Clemens, M. 2002. Machbarkeitsstudie zur räumlichen Niederschlagsanalyse aus Schiffsmessungen über der Ostsee. Dissertation, Institut für Meereskunde an der Christian-Albrechts-Universität Kiel.

Clemens, M. and Bumke, K. 2002. Precipitation fields over the Baltic Sea derived from ship rain gauge measurements on merchant ships. Boreal Environ. Res. 7, ISSN 1239-6095, 425-436. 
Ebert, B. 2005. Validation Working Group Report, Recommendation 4. Eumetsat Proceedings, P.44, Second International Precipitation Working Group Workshop, ISBN 92-9110-070-6, 15-19.

Ferraro, R. 2007. Past, present and future of microwave operational rainfall algorithms. In: Measuring Precipitation from Space, Advances in Global Change Research 28, Eds. V. Levizzani, P. Bauer, and J. Turk, Springer, Dordrecht, The Netherlands, ISBN-13 978-1-4020-5834-9, 189-198.

Großklaus, M. 1996. Niederschlagsmessung auf dem Ozean von fahrenden Schiffen. Dissertation, Institut für Meereskunde an der ChristianAlbrechts-Universität Kiel.

Großklaus, M., Uhlig, K. and Hasse, L. 1998. An optical disdrometer for use in high wind speeds. J. Atmos. Oceanic Technol. 15, 1051-1059.

Hobbs, P. V., Shupe, M. and Uttal, T. 2001. Airborne studies of cloud structures over the Arctic Ocean and comparisons with retrievals from ship-based remote sensing measurements. J. Geophys. Res. 106, 15 029-15044.

Hogan, A. 1994. Objective estimates of airborne snow properties. $J$. Atmos. Oceanic Technol. 11, 432-444.

Huffman, G., Adler, R., Arkin, P., Chang, A., Ferraro, R. and co-authors. 1997. The Global Precipitation Climatology Project (GPCP) combined precipitation dataset. Bull. Am. Met. Soc. 78, 5-20.

Klepp, C.-P., Bakan, S. and Graß1, H. 2003. Improvements of satellite derived cyclonic rainfall over the North Atlantic. J. Climate 16, 657-669.

Klepp, C.-P., Bakan, S. and Graß1, H. 2005. Missing North Atlantic cyclonic precipitation in the ECMWF model and ERA-40 data detected through the satellite climatology HOAPS II. Met. Z. 14, 809-821.

Kummerow, C., Olson, W. S. and Giglio, L. 1996. A simplified scheme for obtaining precipitation and vertical hydrometeor profiles from passive microwave sensors, IEEE Trans. Geosci. Remote Sens. 34, 1213-1232.

Kummerow, C., Hong, Y., Olson, W.S., Yang, S., Adler, R.F. and coauthors. 2001. The evolution of the Goddard Profiling Algorithm (GPROF) for rainfall estimation from passive microwave sensors. $J$. Appl. Meteorology. 40, 1801-1820.

Lempio, G., Bumke, K. and Macke, A. 2007. Measurement of solid precipitation with an optical disdrometer. Adv. Geosci. 10, 91-97.

Levizzani, V., Bauer, P. and Turk, F. J. Eds., 2007. Measuring Precipitation from Space, EURAINSAT and the future. Advances in Global
Change Research, Vol. 28, Springer, Dordrecht, The Netherlands, 724.

Löffler-Mang, M. and Joss, J. 2000. An optical disdrometer for measuring size and velocity of hydrometeors. J. Atmos. Oceanic Technol. 17(2), 130-139.

Lundberg, A. and Halldin, S. 2001. Snow measurements techniques for land-surface-atmosphere exchange studies in boreal landscapes. Theor. Appl. Climatol. 70, 215-230.

Macke, A., Francis, P. N., Mc Farquhar, G. M. and Kinne, S. 1998. The role of ice particle shapes and size distributions in the single scattering properties of cirrus clouds, J. Atmos. Sci. 55(17), 2874-2883.

Mahlke, H. 2007. Niederschlagsmessung mit einem neuartigen optischen Distrometer (Flying Parsivel Sonde), Diplomarbeit, Institut für Meteorologie und Klimaforschung, Karlsruhe, Germany, pp. 122

Marshall, J., Dobson, F., Moore, K., Rhines, P., Visbeck, M. and coauthors. 1998. The labrador sea deep convection experiment. Bull. Amer. Meteor. Soc. 79, 2033-2058.

Oki, T. 1999. The global water cycle. Global Energy and Water Cycles (eds K.A. Browning and R. J. Gurney, Cambridge, University Press, 10-29.

Rudolf, B. and Schneider, U. 2005. Calculation of gridded precipitation data for the global land-surface using in-situ gauge observations. Eumetsat Proceedings, P.44, Second International Precipitation Working Group Workshop, ISBN 92-9110-070-6, 231-247.

Schlosser, C. A. and Houser, P. R. 2007. Assessing a satellite-era perspective of the global water cycle. J. Climate 20(7), 1316-1338.

Sorteberg, A., Kwamto, N. G. and Byrkjedal, D. 2005. Wintertime Nordic Seas cyclone variability and its impact on oceanic volume transports into the Nordic Seas. The Nordic Seas (eds Drange, and co-editors), AGU Monograph, 137-157.

Trenberth, K. E., Smith, L., Qian, T., Dai, A. and Fasullo, J. 2007. Estimates of the global water budget and its annual cycle using observational and model data. J. Hydrometeorol., Special Edition, 8, 758-769, doi:10.1175/JHM600.1.

Wang Z., Sassen, K., Whiteman, D. N. and Demoz, B. B. 2004. Studying altocumulus with ice virga using ground-based active and passive remote sensors, J. Appl. Meteorol. 43, 449-460.

Yang, D., Elomaa, E., Tuominen, A., Aaltonen, A. and Goodison, B. 1999. Wind-induced precipitation undercatch of the Hellmann gauges. Nordic Hydrol. 30(1), 57-80. 